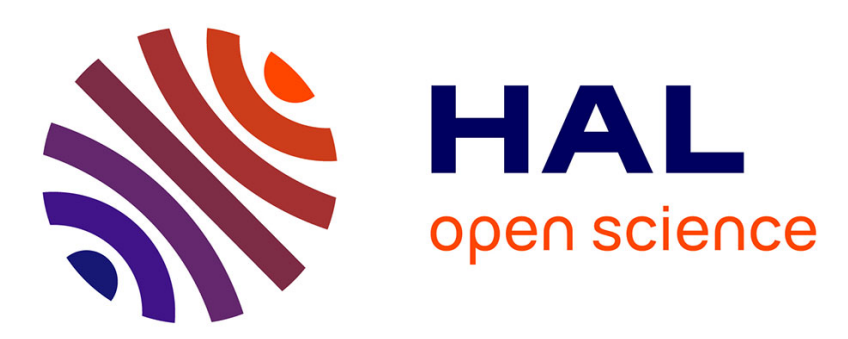

\title{
LOW FREQUENCY RAMAN SCATTERING IN MIXED Ga1-xAlxAs AND Ga1-xInxAs ALLOYS
}

Robert Carles, N. Saint-Cricq, A. Zwick, M. Renucci, J. Renucci

\section{To cite this version:}

Robert Carles, N. Saint-Cricq, A. Zwick, M. Renucci, J. Renucci. LOW FREQUENCY RAMAN SCATTERING IN MIXED Ga1-xAlxAs AND Ga1-xInxAs ALLOYS. Journal de Physique Colloques, 1981, 42 (C6), pp.C6-105-C6-107. 10.1051/jphyscol:1981633 . jpa-00221569

\section{HAL Id: jpa-00221569 https://hal.science/jpa-00221569}

Submitted on 1 Jan 1981

HAL is a multi-disciplinary open access archive for the deposit and dissemination of scientific research documents, whether they are published or not. The documents may come from teaching and research institutions in France or abroad, or from public or private research centers.
L'archive ouverte pluridisciplinaire HAL, est destinée au dépôt et à la diffusion de documents scientifiques de niveau recherche, publiés ou non, émanant des établissements d'enseignement et de recherche français ou étrangers, des laboratoires publics ou privés. 


\title{
LOW FREQUENCY RAMAN SCATTERING IN MIXED Ga $1-x I_{x} A s$ AND $G_{1-x} I_{x}$ As ALLOYS
}

R. Carles, N. Saint-Ċricq, A. Zwick, M.A. Renucci and J.B. Renucci

Laboratoire de Physique des Solides, Associé au C.N.R.S., Université Paul Sabatier, 31062 Toulouse cedex, France

\begin{abstract}
We report Raman studies of disorder induced scattering in the $\overline{\mathrm{Ga}_{1-\mathrm{X}} \mathrm{AI}} \mathrm{As}$ and $\mathrm{Ga}_{1-\mathrm{X}} \mathrm{In}_{\mathrm{X}} \mathrm{As}$ alloys. Previous results [1] are confirmed for the $\mathrm{Ga}_{1-\mathrm{X}} \mathrm{Al}$ As system for $\mathrm{a}$ wider range of concentration. The role of the substituant is discussed through the analys is of the $G a_{1-x} \operatorname{In}_{\mathrm{X}}$ As system.
\end{abstract}

Introduction. - To extend results on a $\mathrm{Ga}_{0.80^{\mathrm{Al}}} 0.20^{\mathrm{As}}$ crystal [1] we performed experiments to a concentration of $\mathrm{Al}$ equals 0.50 . Hass and size effects related to the nature of the substituant are analyzed on the $\mathrm{Ga}_{1-\mathrm{x}} \mathrm{In}_{\mathrm{x}} \mathrm{As}$ system.

Results and discussion.- All experimental details are provided in reference [1]. All the samples used in the present work were layers L.P.E. grown on a the (100) face of GaAs substrate.

Figures 1 and 2 display, respectively, the results obtained, at $300 \mathrm{~K}$, for $\mathrm{Ga}_{1-\mathrm{x}} \mathrm{Al} \mathrm{x}_{\mathrm{As}}$ and $\mathrm{Ga}{ }_{1-\mathrm{x}} \mathrm{In}_{\mathrm{x}} \mathrm{As}$. Although the exciting laser wavelengths are different (see figure captions) resonance effects are excluded.

As in reference [1] we find that, except for the GaAs $L O(\Gamma)$ mode, the crystalline symmetry is also lost for the $\mathrm{Ga}_{1-\mathrm{x}} \operatorname{In}_{\mathrm{x}} \mathrm{As}$ alloys. Therefore we give only two types of spectra in figures 1 an 2. a(b) refers to crossed (parallel) polarizations of the incident and scattered lights and corresponds to the $\Gamma_{15}\left(\Gamma_{1}+4 \Gamma_{12}\right)$ Raman cross section [1].

Let us first compare for the same concentration $(x=0.20)$ the spectra of the two alloys.

The main effect of the substituant appears for the long wavelength optical modes and is related to mass effects $\left(m_{A I}<m_{G a}<m_{I n}\right)$. Indeed a AlAs-like band stems above the frequency of the $I O(\Gamma)$ in GaAs. This band merges into the local mode of Al in GaAs as $x$ reaches zero. On the contrary for the $G a_{1-x} I_{x}$ As compounds a structure shows up below the $L O(\Gamma)$ around $235 \mathrm{~cm}^{-1}$. It gives for $x=0.09$ a shoulder (fig. 2) which materializes clearly the impurity mode of In in GaAs. As there is no gap in the phonon density of states of GaAs [2] it is an in-band mode and denoted $\omega_{b}$ (In:GaAs). The symmetry of this mode is $\Gamma_{15}$ (see fig. 2) as expected theoretically.

The structure at $265 \mathrm{~cm}^{-1}$ (fig. 1), which is attributed in reference [1] to GaAs 


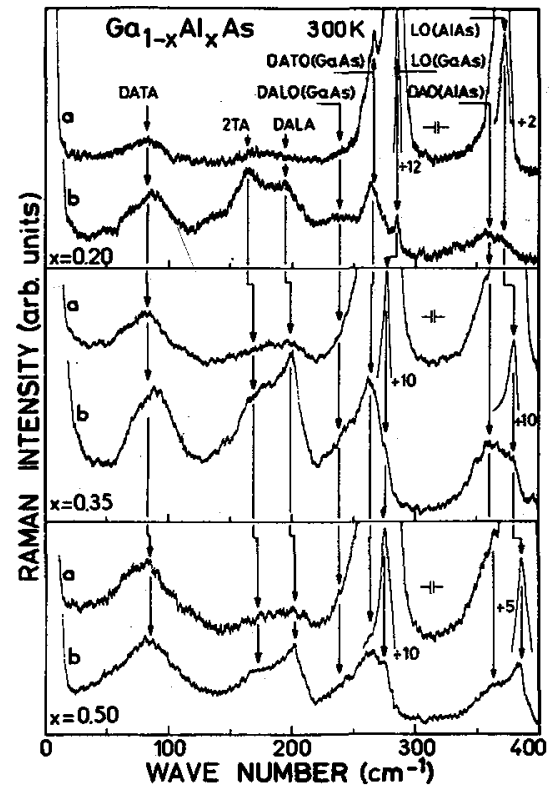

Fig. 1-Raman spectra observed, at

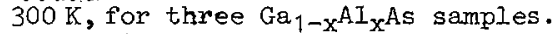
The exciting laser wavelengths are $\lambda=5308 \AA$ for $x=0.20$ and $\lambda=5145 \AA$ for $\mathrm{x}=0.35$ and 0.50 .

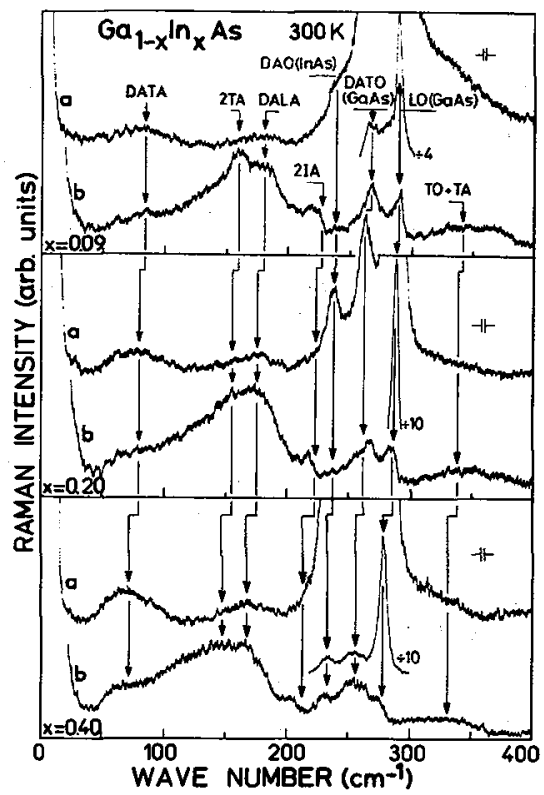

Fig. 2 - Raman spectra observed, at $300 \mathrm{~K}$, for three $\mathrm{Ga}_{1-\mathrm{x}} \operatorname{In}_{\mathrm{X}} \mathrm{As}$ samples. The exciting laser wavelengths are $\lambda=4880 \AA$ for $x=0.09$ and $x=0.20$, $\lambda=5308 \AA$ for $\mathrm{x}=0.40$.

disorded activated transverse optical processes (D.A.T.O.), is also present in the $\mathrm{Ga}_{1-\mathrm{x}} \mathrm{In}_{\mathrm{x}} \mathrm{As}$ system (fig. 2) whereas the D.A.L.O. of GaAs (fig. 1) is obscured by the InAs-like band. This one is noted D.A.O. ( $\mathrm{fig} .2$ ) as it is hard to distinguish between longitudinal and transverse processes.

In the low frequency range the D.A.T.A., 2 TA, and D.A.L.A. modes appear also in the $\mathrm{Ga}_{1-\mathrm{x}} \mathrm{In}_{\mathrm{x}} \mathrm{As}$ alloys although the structures are less resolved. Their frequencies are shifted to lower energies compared to those found in GaAs [1], due to mass effects, as expected. They increase in $\mathrm{Ga}_{1-\mathrm{x}} \mathrm{Al}_{\mathrm{x}} \mathrm{As}$ for the same reason.

The shift to lower energy of the acoustical branches in the $\mathrm{Ga}_{1-\mathrm{x}} \mathrm{In}_{\mathrm{x}}$ As system allows to resolve the $2 \mathrm{IA}$ band while it lies within the D.A.L.O. of GaAs for $\mathrm{Ga}_{1-\mathrm{x}^{\mathrm{Al}} \mathrm{x}} \mathrm{As}$.

The assignement of the structures discussed above for $\mathrm{x}=0.20$ are confirmed by the variations of their frequencies, widths and intensities upon concentration.

As already mentionned spectra are less structured for the $\mathrm{Ga}_{1-\mathrm{x}} \operatorname{In}_{\mathrm{x}} \mathrm{As}$ system. In the acoustical range this is related, in part, to the larger width of the $2 \mathrm{TA}$ band. Due to the bigger size of $\mathrm{In}$, the substitution of In to Ga introduces a distorsion 
of the bond length ruch more important than the one produced by the substitution of Al (the bond lengths in GaAs, AlAs and InAs are respectively $2.447 \AA, 2.452 \AA$ and $2.615 \AA)$. This effect induces a larger amount of disorder in the $\mathrm{Ga}_{1-\mathrm{x}} \mathrm{In}_{\mathrm{X}} \mathrm{As}$ system and consequently should lead to wider structures.

The same reason could explain that, for each concentration, the width of the D.A.T.A. is larger by an amount of $7 \mathrm{~cm}^{-1}$, on the average, in the $\mathrm{Ga}_{1-\mathrm{x}} \mathrm{In}_{\mathrm{x}}$ As alloys. In the same way, the width of the LO(GaAs) band increases by a factor $2.7(1.8)$ when the concentration of $\mathrm{In}(\mathrm{Al})$ goes from 0 to 0.5 .

The intensities of the disorder induced bands reflect the degree of disorder of the alloy. As a matter of fact the relative intensities of the D.A.T.A. and the D.A.L.A. to that of the $2 \mathrm{TA}$ band increase ( $\mathrm{fig}$. 1 and 2) with $\mathrm{x}$ as the latter is reminescent of the order of the perfect crystal. To evaluate more quantitativeiy the degree of disorder it is convenient to refer to the intensity of the D.A.T.A. which is well seen in the two alloys. Indeed the ratio I(D.A.T.A.)/(1-x)I [ LO(GaAs)] increases with $x$.

In figures $1-b$ one notices also that the intensities of the D.A.L.O. and the D.A.T.O. of GaAs increase in a way similar to that of the D.A.I.A. Also the D.A.O. of AlAs get stronger with $x$.

The "depolarization spectrum" introduced by Kobliska and Solin in the case of amorphous materials [3] can be measured in the alloys. As all the spectra have been recorded with the same instrumental transfer fonction, for each concentration, the depolarization ratio $\rho$ is given by the ratio of the intensity of spectrum a over that of spectrum b. One deduces from fig. 1 and 2 that $\rho$ (D.A.T.A.), for example, increases with $x$ and reaches its maximum value when the disorder is the greatest for $x=0.5$. As displays in figures 1 and $2 \rho$ is dispersive, indeed $\rho$ (D.A.L.A.) < (D.A.T.A.). This implies that the vibrations which correspond to the D.A.L.A. are more symetrical than those of the D.A.T.A. in agreement with the conclusions of London [4] relative to defect activated Raman processes in zinc-blende type crystals. As a matter of fact, although longitudinal and transverse acoustical phonons at $X$ and $I$ become Raman active, the symmetry of the longitudinal is in part $\Gamma_{1}$-like while the one of the transverse is never $\Gamma_{1}$. One should point out that the $\Gamma_{1}$ symmetry of the D.A.L.A. was well reproduced by the calculations of Talwar et al. [5].

\section{References.-}

[1] N. SAINT-CRICQ, R. CARLES, J.B. RENUCCI, A. ZWICK and M.A. RENUCCI, Solid state commun., in print.

[2] J.L.T. WAUGH and G. DOLLING, Phys. Rev., 132, 2410 (1963).

[3] R.J. KOBLISKA and S.A. SOLIN, Phys. Rev. B, 8,736 (1973).

[4] R. LONDON, Proc. Phys. Soc., 84,379 (1964)

[5] D.N. TALWAR, M. VANDEVYVER and M. ZIGONE, Phys. Rev. B, 23,1743 (1981). 